I-Economic Vol. 4. No 2. Desember 2018

Faktor yang Mempengaruhi Pola Konsumsi .... Amir Machmud

\title{
Faktor Yang Mempengaruhi Pola Konsumsi Mayarakat Miskin Dalam Perspektif Islam
}

\author{
Amir Machmud*1, Eeng Ahman ${ }^{2}$, \\ ${ }^{1,2}$ Universitas Pendidikan Indonesia, \\ e-mail: *11amir@upi.edu,,$\underline{2}$ eengahman@upi.edu
}

\begin{abstract}
Factors that influence the consumption pattern of the poor in Islamic perspective have been analyzed in depth in this study. Inventory variables refer to the concept; Al-Ghazali which consists of aql, qalb and nafs. These three variables \& nbsp; asymmetrically affect the tendency of consumption patterns. \& nbsp; This study uses an explanatory survey method with data collection techniques through questionnaires and interviews. The population of 68 people who are recipients of zakat distributed by the Zakat Agency Bandung City. The data that has been collected is then analyzed by multiple regression. The results of the study show that consumption patterns \& nbsp; poor people in Indonesia (Bandung City, West Java) are influenced by Aql, Qalb and Nafs. These three factors significantly and positively affect consumption patterns of the poor in the city of Bandung. This finding implies that the consumption of society should be Simple behavior. In accordance with Islamic principles, always instill within that the treasure given by God is merely a deposit and is not easily influenced by fashion.
\end{abstract}

Keywords: Consumption Patterns, Poverty, Aql (reason), Qalb and Nafs.

\begin{abstract}
Abstrak
Faktor-faktor yang mempengaruhi pola konsumsi masyarakat miskin dalam perpektif islam telah dianalisis secara mendalam dalam kajian ini. Variabel yang diinventarisir mengacu pada konsep Al-Ghazali yang terdiri dari aql, qalb dan nafs. Ketiga Variabel tersebut secara asimetris mempengaruhi kecenderungan pola konsumsi. Kajian ini menggunakan metode survey eksplanatory dengan teknik pengumpulan data melalui kuesioner dan wawancara. Populasi sebanyak 68 orang yang merupakan para penerima zakat yang disalurkan oleh Badan Amil Zakat Kota Bandung. Data yang telah dikumpulkan selanjutnya dianalisis dengan regeresi berganda. Hasil kajian menunjukkan bahwa pola konsumsi masyarakat miskin di Indonesia (Kota Bandung Jawa Barat) dipengaruhi oleh Aql, Qalb dan Nafs. Ketiga faktor tersebut secara signifikan dan berpengaruh positif terhadap pola konsumsi masyarakat miskin d Kota Bandung.Temuan ini mmberikan implikasi bahwa dalam berkonsumsi masyarakat hendaknya Berperilaku sederhana yang sesuai dengan prinsip islam, selalu menanamkan dalam diri bahwa sesungguhnya harta yang diberikan oleh Allah hanyalah titipan semata, dan tidak mudah terpengaruh oleh mode.
\end{abstract}

Kata kunci: Pola Konsumsi, Kemiskinan, Aql (akal), Qalb dan Nafs. 
I-Economic Vol. 4. No 2. Desember 2018

Faktor yang Mempengaruhi Pola Konsumsi .... Amir Machmud

\section{Pendahuluan}

Gaya hidup masyarakat Indonesia saat ini sudah mengikuti gaya hidup negaranegara maju, gaya hidup yang hedonis menyebabkan masyarakat berperilaku konsumtif. Kondisi ini didukung pula oleh semakin berkembangnya tempat rekreasi, wisata kuliner dan tempat perbelanjaan yang menjamur di lingkungan sekitar. Sebagai salah satu negara dengan penduduk muslim terbesar didunia harusnya masyarakat Indonesia berperilaku sesuai dengan prinsip-prinsip syariah, karena dengan jumlah penduduk muslim yang besar ini akan lebih mudah dalam menjalankan dan mengamalkan nilainilai islam, lingkungan yang islami mampu membentengi seseorang dari perbuatan atau perilaku yang mengarah pada pola perilaku yang konsumtif. ${ }^{1}$

Kondisi tersebut berlaku pula pada masyarakat para penerima zakat melalui BAZ yang menunjukkan penggunaan dari zakat yang diterima semata untuk memenuhi kebutuhan yang tidak lagi didasarkan atas kebutuhan untuk meningkatkan ibadah kepada Allah SWT, melainkan pada kebutuhan yang bersifat bermuara pada perilaku konsumtif. ${ }^{2}$ Presentasi dari kebutuhan akan pangan mencapai $46 \%$, kebutuhan akan kesenangan sebesar $25 \%$, kebutuhan akan pendidikan sebesar $14 \%$ kebutuhan akan menabung dan berjaga-jaga sebesar $11 \%$ dan menyisihkan sebagian rezekinya untuk sedekah dan infak sebesar $4 \%$ saja.

Islam sebagai the way of life telah memberikan arahan yang sangat indah dalam berkonsumsi yaitu dengan memperkenalkan konsep israf (berlebih-lebih) dalam membelanjakan harta dan tabzir. Islam memperingatkan agen ekonomi agar jangan sampai terlena dalam berlomba-lomba mencari harta (at-takaatsur). Islam membentuk jiwa dan pribadi yang beriman, bertaqwa, bersyukur dan menerima. Pola hidup konsumtif seperti di atas tidak pantas dan tidak selayaknya dilakukan oleh pribadi yang beriman dan bertaqwa. Satu-satunya gaya hidup yang cocok adalah simple living ( hidup sederhana) dalam pengertian yang benar secara syar'i. ${ }^{3}$

\footnotetext{
${ }^{1}$ Amir Machmud, Eeng Ahman, Navik Istikomah, "Optimalization of Qardhu Hasan Sharia Bank toward Decreasing Poverty in Bandung”. Proceedings of the 2016 Global Conference on Business, Management and Entrepreneurship, Atlantis Press, 2016

E.Suprayitno dkk "The imfact of Zakat on Aggregate Consumption in Malaysia". Journal of Islamic Economics, Banking and Finance, 56 Vol. 9 No. 1, Jan - Mar 2013

Warde, A.. "Consumption and Theories of Practice", Journal of Consumer Culture, Vol. 5, No. 2 pp. 131-153. 2005

2 Amir Machmud, "Sharia Microfinance, Poverty, Indonesia”, Proceedings of the 2nd International Conference on Economic Education and Entrepreneurship August 3-3, 2017, in Bandung, Indonesia

Bappenas "Perkembangan Keuangan Mikro Untuk Kemiskinan". http:// ditpk.bappenas.go.id/ ?nav $=4 \& m=$ content $\& s=$ artikel $\& a=$ view $\& i d=309(2010)$

3 Yusuf al-Qardhawy Konsep Islam dalam Mengentaskan kemiskinan. (Surabaya, Bina Islam. 1996)

Lee Roy Beach and Terry Connolly, The Psychology of Decision Making, USA, Sage Publication, 2005

E.Suprayitno, dkk “ The imfact of Zakat on Aggregate Consumption in Malaysia”. Journal of Islamic Economics, Banking and Finance, 56 Vol. 9 No. 1, Jan - Mar 2013
} 
Berdasasarkan fenomena tersebut, timbul pertmasalahan utama yaitu faktorfaktor apa yang mempengaruhi pola konsumsi masyarakat ditinjau dari perspektif islam, kemudian sampai sejauhmana faktor-faktor tersebut mempengaruhi terhadap perilaku konsumsi masyarakat penerima BAZ.

Kajian ini dimaksudkan untuk mengumpulkan, mengolah dan menganalisis data yang berhubungan dengan faktor-faktor yang mempengaruhi perilaku masyarakat miskin. Di Kota Bandung. Penelitian ini diharapkan dapat memberikan kemanfaatan baik bagi aspek teoritis maupun aspek praktis. Secara teoritis, penelitian ini diharapkan dapat memberikan sumbangan pemikiran untuk memperkaya khasanah ilmu ekonomi islam, khususnya terkait dengan pola konsumsi dalam pandangan islam, Secara praktis diharapkan penelitian ini dapat memberikan gambaran serta informasi mengenai faktorfaktor yang mempengaruhi pola konsumsi dalam pandangan islam. Juga dapat memberikan masukan bagaimana mengalokasikan anggarannya untuk memenuhi kebutuhannya secara bijak

\section{A. Konsumsi dalam Pandangan Al-Ghazali}

Menurut Imam Al-Ghazali dalam Muhammad Muflih (2006:51) bahwa manusia pada dasarnya terdiri dari empat unsur yaitu Ruh, Nafs, 'Aql, dan Qalb. ${ }^{4}$ Setiap unsur tersebut memiliki aktifitas yang berbeda, tetapi satu sama lain saling berhubungan dalam membentuk karakter seseorang. Baik atau buruknya karakteristik seseorang tergantung pada tingkat kesehatan aql, qalb dan nafsnya. Semakin sehat ketiga variable tersebut, maka semakin baik karakternya, dan sebaliknya. Tingkat kesehatan aql, qalb dan nafs tersebut tidak muncul dengan sendirinya, melainkan dengan cara dilatih terlebih dahulu. Keterpaduan empat unsur manusia yang terlatih tersebut mampu mendorong kemajuan tingkat keislaman, keamanan, dan ketakwaan seseorang.

$\mathrm{A} q l$ atau rasio merupakan alat berpikir manusia dalam berperilaku. Perilaku manusia yang rasional dpat ditinjau dari dua aspek yaitu rasional dalam metode dan rasional dalam hasil. Pada aspek metode, perilaku manusia dikatakan rasional jika tindakan yang dilakukan manusia berdasarkan pikiran yang beralasan, bukan berdasarkan kebiasaan, prasangka dan emosi. Berbeda dengan aspek hasil, perilaku manusia dikatakan rasional, jika tindakan yang benar-benar dapat mencapai tujuan yang ingin dicapai berupa maslaha yakni kesejahteraan di dunia dan akhirat. Untuk mencapai kemaslahaan tersebut, fungsi tujuan konsumen muslim rasional mencapai maksimum tidak hanya dengan mengkonsumsi sejumlah barang dan menguasai sejumlah barang tahan lama, melainkan juga bahkan lebih diharapkan adalah membelanjakan pendapatannya untuk amalan shaleh sesuai yang dikehendaki Allah.Swt.

\footnotetext{
${ }^{4}$ Muhamad Muflih, Perilaku Konsumen dalam Perspektif Ekonomi Islam (Jakarta, RajaGrafindo, 2006)
} 
Qalbu atau Rasa merupakan perasaan manusia. Perasaan ini mencakup perasaan manusia terhadap Tuhannya, sehingga diperlukan keimanan dan ketakwaan. Dari rumusan ini dapat disimpulkan bahwa orang yang dekat dengan Tuhan berimplikasi pada kedekatannya dengan manusia, begitu pula sebaliknya. Peranan keimanan menjadi tolak ukur penting karena keimanan memberikan pandangan dunia yang cenderung mempengaruhi kepribadian manusia dalam bentuk perilaku, gaya hidup,selera, sikap-sikap terhadap sesama manusia, dan ekologi. Keimanan sangat mempengaruhi sifat, kuantitas, dan kualitas konsumsi, baik dalam bentuk kepuasan material maupun spiritual. Inilah sebagai bentuk upaya meningkatkan keseimbangan antara orientasi duniawi dan ukhrowi. Keimanan memberikan saringan moral dalam membelanjakan harta dan sekaligus juga memotivasi pemanfaatan sumberdaya (pendapatan) untuk hal-hal yang efektif. Saringan moral bertujuan menjaga kepentingan diri tetap berada didalam batas-batas kepentingan sosial dengan mengubah preferensi individual semata menjadi preferensi yag serasai antara individual dan sosial, serta termasuk pula saringan dalam rangka mewujudkan kebaikan dan kemanfaatan. Dalam konteks inilah kita dapata berbicara tentang bentuk-bentuk konsumsi halal haram, pelarangan terhadap bermewah-mewahan dan bermegah-megahan, konsumsi sosial, dan aspek normatif lainnya.

Nafsu merupakan sifat tercela yang ada pada diri manusia baik secara jasmani maupun rohani. Nafs dapat dikelompokkan kedalam nafsu muthmainnah (jiwa yang tenang), nafsu lawwamah (jiwa yang mencela) dan nafsu amarah. Dalam hubungannya dengan pola konsumsi, nafs merupakan pengendalian dari sifat-sifat yang akan membuat manusia menjadi konsumtif dalam melakukan konsumsi. Kondisi ini dipengaruhi oleh 1) Jiwa tumbuhan (an nafs an-nabatiyah) dengan daya-daya Makan, Tumbuh dan Berkembang biak 2) Jiwa binatang (an-nafs al-hayawaniyatu) dengan sifat Gerak dan Menangkap, dan 3) Jiwa manusia dengan sifat Praktis (al-'alimatu) yang hubungannya dengan badan dan Teoretis (al-alimatu atau an-nazariyyatu) yang hubungannya dengan hal-hal abstrak.

Berdasarkan ketiga variable tersebut, dapat ditarik kesimpulan sebagai dasar hipotesis bahwa seseorang yang boros menyerupai binatang, yang kadang-kadang boros kadang-kadang hemat, kadang-kadang menyerupai binatang, tapi masih ada harapan bagi dirinya untuk berubah melalui pembaruan cara berpikr dan bertindak, dan yang hemat mendekati kesempurnaan. Keiga hubungan variable tersebut dapat digambarkan pada bagan berikut ini:

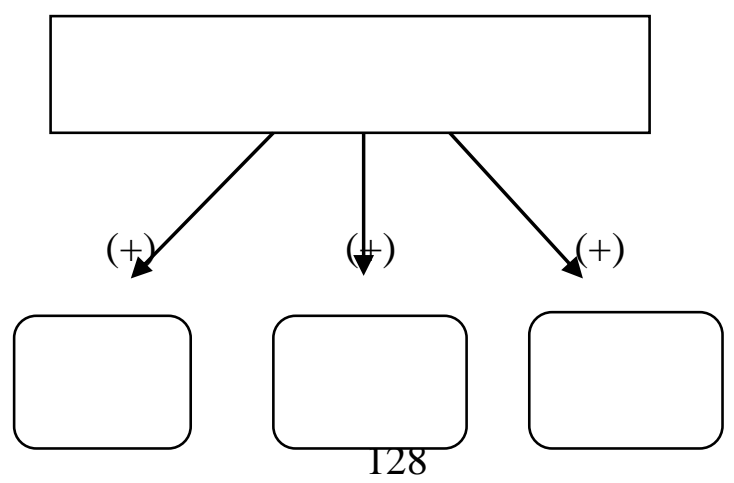


I-Economic Vol. 4. No 2. Desember 2018

Faktor yang Mempengaruhi Pola Konsumsi .... Amir Machmud

\section{Gambar 1 Korelasi IMTAQ Dengan Unsur Unsur Manusia Tuan A}

Tingkat keimananan dan ketakwaan seseorang mempengaruhi unsur aql, nafs, dan qalbnya. Bila keimanan dan ketakwaannya positif maka ketiga unsur manusia tersebut akan positif pula yang berdampak pada pola konsumsi yang hemat. Sebaliknya jika keimanan dan ketakwaanya negative maka pola konsumsinya akan cenderung bersifat boros karena aql, nafs dan qalb-nya negative. ${ }^{5}$

\section{Metode Penelitian}

Kajian ini menggunakan metode survey eksplantori (Eksplanatory methode), dengan teknik pengumpulan data melalui kuesioner dan wawancara. Populasi sebanyak 68 orang, mereka para penerima zakat dari BAZ Kota Bandung. Instrument penelitian yang digunakan dalam penelitian ini adalah angket tentang aql, nafs, qalb dan pola konsumsi. Skala yang digunakan dalam instrumen penelitian ini adalah skala likert. Selanjutnya agar hasil penelitian tidak bias dan diragukan kebenarannya maka alat ukur tersebut harus valid dan reliabel. Untuk itulah terhadap angket yang diberikan kepada responden dilakukan 2 (dua) macam tes, yaitu tes validitas dan tes reliabilitas.

Data yang telah dikumpulkan selanjutnya dianalisis dengan sistem skoring dan analisis regresi berganda. Sistem skoring digunakan untuk mengetahui gambaran secara umum tentang pola konsumsi masyarakat miskin di Kota Bandung, sedangkan analisis regresi berganda untuk mengetahui faktor-faktor yang mempengaruhi pola konsumsinya.

5 Rashid, M. Z. and Ibrahim, S. "The Effect of Culture and Religiosity on Business Ethics: A CrossCultural Comparison", Journal of Business Ethics, 82, pp. 907-917, 2008,

Alas, R.,"The Impact of Work-Related Values on the Readiness to Change in Estonian Organization", Journal of Business Ethics, Vol. 86, pp. 113-124, 2009

Foxall, R. G., Sigurdsson, V. "Consumer Behavior Analysis: Behavioral Economics Meets The Marketplace”, The Psychological Record, Vol. 63, pp. 231-238. 2013.

Scott John Vitell, et.al, "Religiosity and Moral Identity: The Mediating Role of Self-Control", Journal of Business Ethics, 88, pp 604; 2009

Mokhlis, S., "Relevancy and Measurement of Religiosity in Consumer Behavior Research", International Business Research, Vol. 2, No.3, p. 75- 84, 2009

Rohman \& Taufik Ismail, "Consumption Ritual in Javanese Wedding Ceremony: Ethnography Research in Indonesian Regency-Kabupaten Ngawi, Asia Pasific Management and Business Application, 2, (2) 2013,

Emerson and McKinney, "Importance of Religious Beliefs to Ethical Attitudes in Business", Journal of Religion and Business Ethics, Vol 1. Issue 2. , 2010.

Komaruddin Hidayat, Psikologi Beragama, Menjadikan Hidup Lebih Nyaman dan Santun, (Jakarta: PT Mizan Publika, 2006, hlm. 53). 
Model analisis yang digunakan adalah Regresi berganda yang diestimasi dengan ordinary least squweres (OLS). Untuk membuktikan bahwa koefisien regresi dari setiap model baik (goodness fit) secara parsial maupun bersama-sama digunakan uji t dan uji F, dengan level of significant $5 \%$. Untuk mengetahui apakah terdapat pelanggaran asumsi dalam model persamaan, maka digunakan beberapa pengujian yang berkaitan dengan multikolineritas, heteroskedastis, dan autokorelasi. Di samping itu, untuk mengestimasi model persamaan dalam penelitian ini digunakan koefisien unstandardized dan standardized. Secara fungsional hubungan antara variabel-variabel dalam penelitian ini mengikuti persamaan berikut ini.

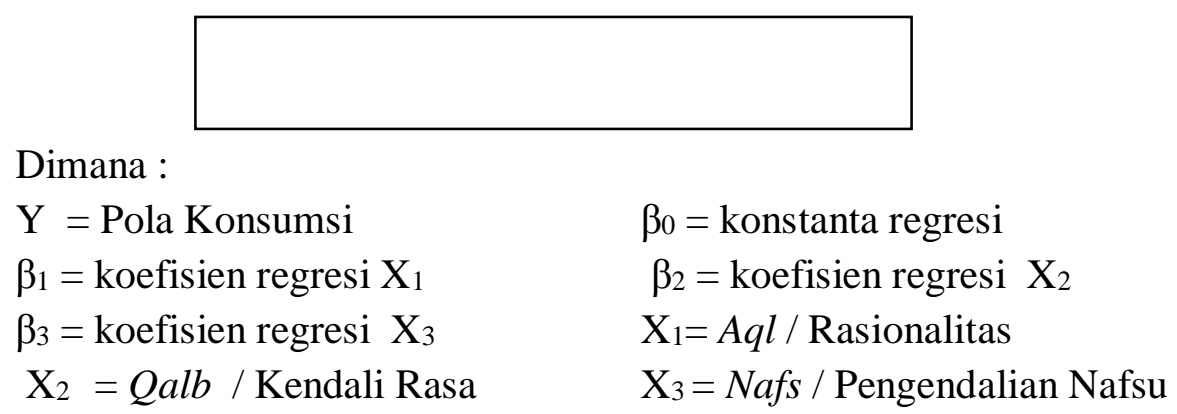

\section{Hasil dan Pembahasan}

\section{Gambaran Umum Responden Masyarakat Miskin Kota Bandung.}

Berdasarkan hasil temuan masyarakat penerima zakat dari BAZ Kota Bandung terdiri dari responden perempuan sebesar $79 \%$ dan sisanya sebesar $21 \%$ merupakan responden laki-laki. Ditinjau dari tinkat usia, para responden sebagan besar ( $72 \%$ ) termasuk ke dalam usia yang produktif, sedangkan sisanya sebesar $28 \%$ usia tidak produktif. Kondisi ini memberikan indikasi bahwa para responden memiliki kemampuan untuk menggunakan dengan optimal tenaganya dalam melakukan kegiatan baik kegiatan untuk menghasilkan pendapatan ataupun kegiatan untuk mengkonsumsikan pendapatan yang dimilikinya. Lebih jelas keadaan tersebut dapat dilihat pada Gambar 1 dan Gambar 2. 
I-Economic Vol. 4. No 2. Desember 2018

Faktor yang Mempengaruhi Pola Konsumsi .... Amir Machmud

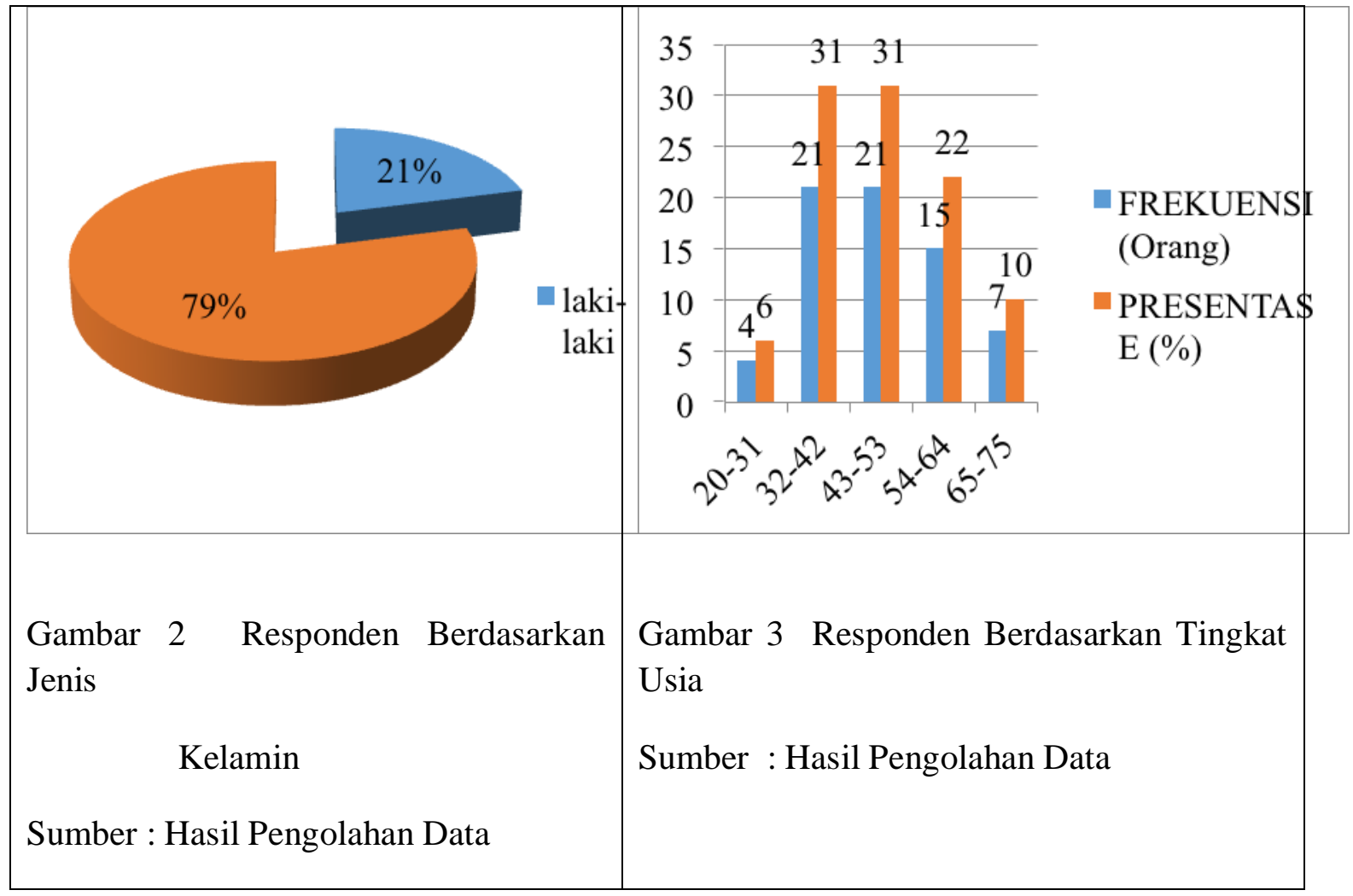

Status kepemilikan rumah masyarakat penerima zakat dari BAZ Kota Bandung terbagi menjadi tiga bagian, yaitu rumah milik sendiri, kontrak/sewa, dan milik orang tua. Sebagian besar responden sudah menempati rumah sendiri yaitu sebanyak 40 orang (59\%) dan sisanya menempati rumah kontrak/sewa sebanyak 15 orang (22\%) serta rumah milik orang tua sebanyak 13 orang (19\%). Ditinjau dari aspek pendapatan yang diterima responden sebagian besar responden menerima pendapatan di bawah Rp. 1 juta, ini menunjukkan bahwa mereka tergolong orang miskin berdasarkan kriteria BPS. Lebih jelas dapat dilihat pada gambar 3 dan Gambar 4.

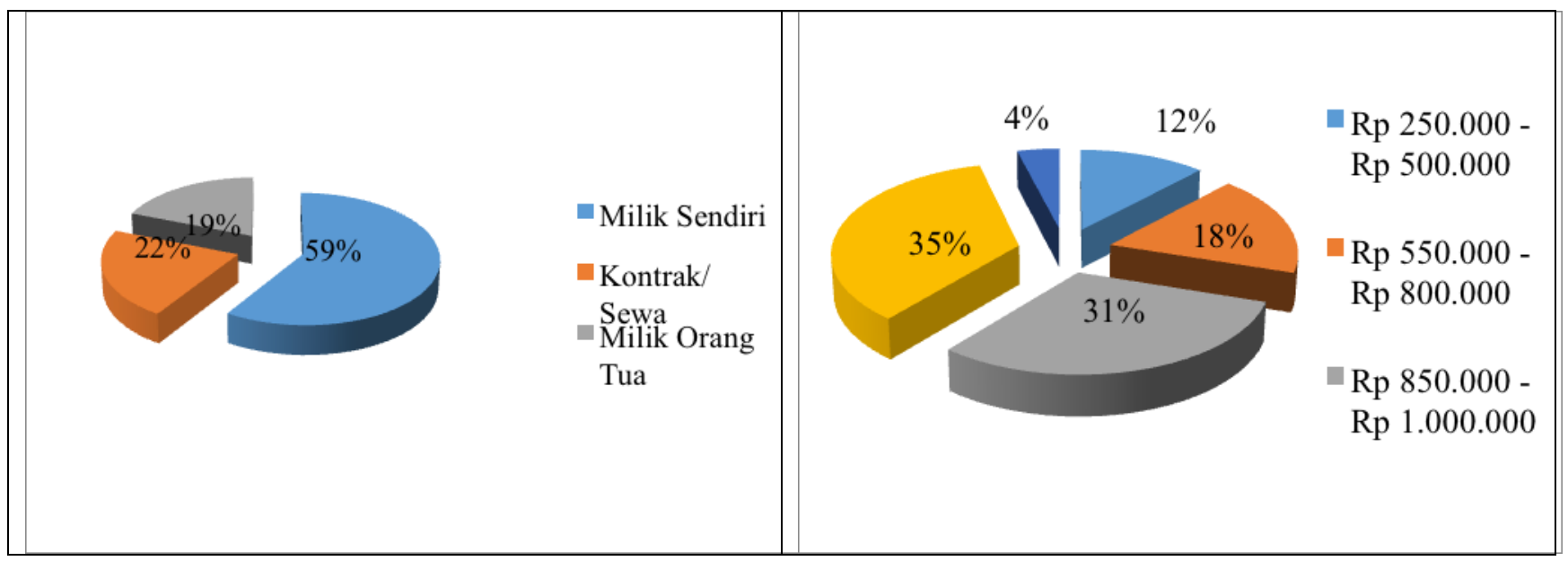


I-Economic Vol. 4. No 2. Desember 2018

Faktor yang Mempengaruhi Pola Konsumsi .... Amir Machmud

\begin{tabular}{|l|l|}
\hline $\begin{array}{l}\text { Gambar } 3 \text { Responden Berdasarkan Kepemilikan } \\
\text { Rumah }\end{array}$ & $\begin{array}{l}\text { Gambar 4 Responden Berdasarkan Pendapatan } \\
\text { Sumber : Hasil Pengolahan Data }\end{array}$ \\
Sumber : Hasil Pengolahan Data &
\end{tabular}

Berdasarkan data banyaknya tanggungan keluarga, sebagian besar responden mempunyai tanggungan sebesar 2 oramg yaitu sebesar $43 \%$. Adapun responden yang sama sekali tidak memiliki tanggungan, tetapi jumlahnya hanya sedikit yaitu sebesar $4 \%$. Sisanya responden yang memiliki 1 orang tanggungan sebanyak $6 \%, 3$ orang tanggungan sebanyak 25\%, 4 orang tanggungan sebanyak $9 \%$, dan responden yang memiliki 5 orang tanggungan sama besarnya dengan 6 orang tanggungan yaitu sebesar 1\%. Berdasarkan Gambar 4.6 dapat diketahui bahwa kebanyakan masyarakat penerima zakat di BAZ Kota Bandung mengeluarkan pendapatannya untuk kebutuhan pangan yaitu sebesar $71 \%$ sedangkan untuk kebutuhan sandang dan papan masing-masing sebesar $14 \%$ dan $15 \%$.

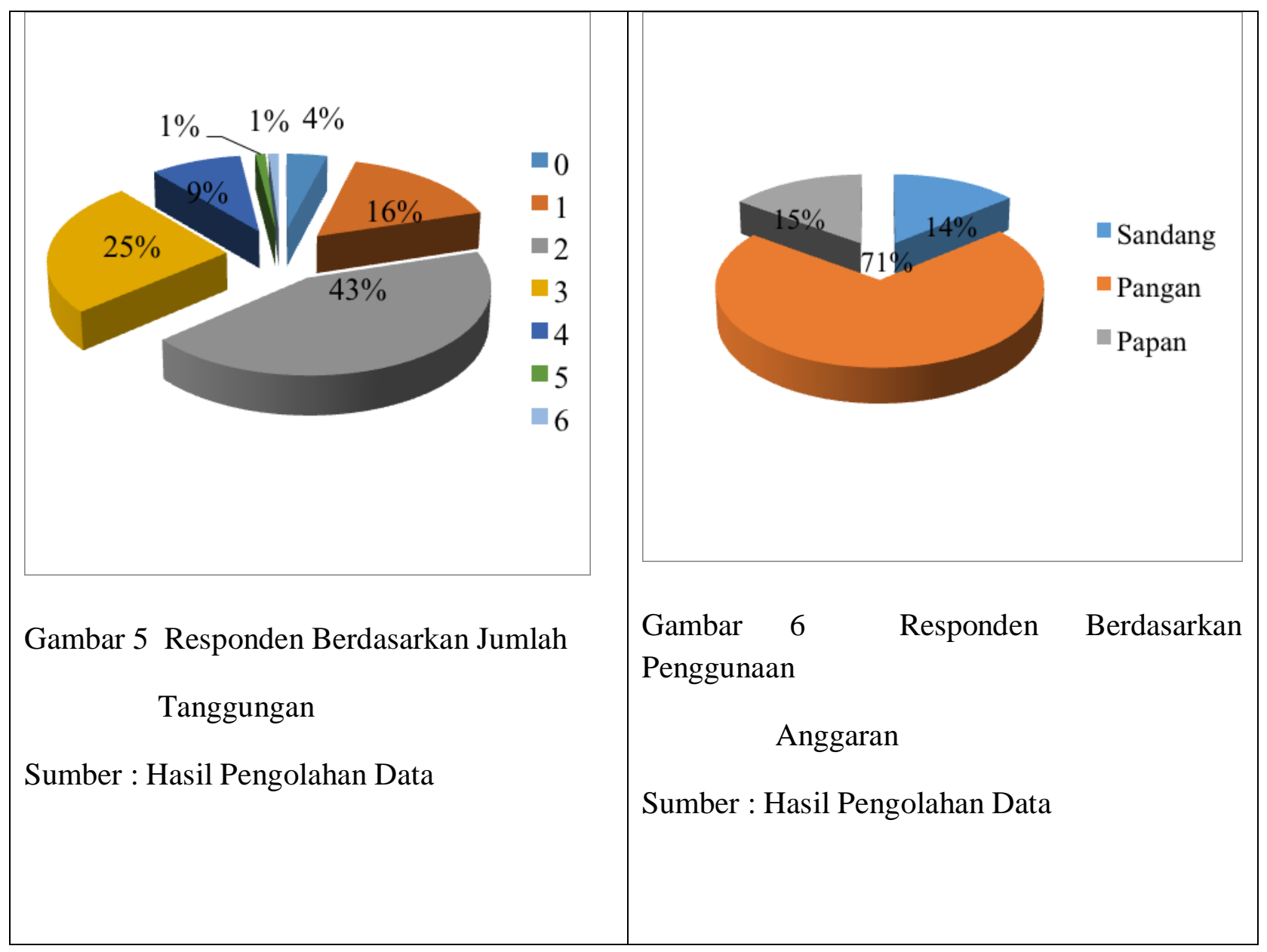


I-Economic Vol. 4. No 2. Desember 2018

Faktor yang Mempengaruhi Pola Konsumsi .... Amir Machmud

\section{Faktor-faktor yang Mempengaruhi Pola Konsumsi Masyarakat Miskin Kota Bandung}

Sebelum menganalisis tentang faktor-faktor yang mempengaruhi pola konsumsi masyarakat miskin kota Bandung, pada bagian ini akan diuraikan hasil uji asumsi klasik terhadap variabel-variabel. Uji asumsi klasik bertujuan untuk mengetahui kondisi data yang dipergunakan dalam penelitian ini data bersifat BLUE. Beberapa uji yang dilakukan adalah Uji Normalitas, Multikolinieritas, Uji Heteroskedastisitas, dan Uji Autokorelasi. Semua uji asumsi klasik terlebih dahulu dilakukan peningkatan data dari ordinal ke interval dengan menggunakan MSI. Hasil perhitungan asumsi klasik dapat dilihat pada table berikut ini. 
I-Economic Vol. 4. No 2. Desember 2018

Faktor yang Mempengaruhi Pola Konsumsi .... Amir Machmud

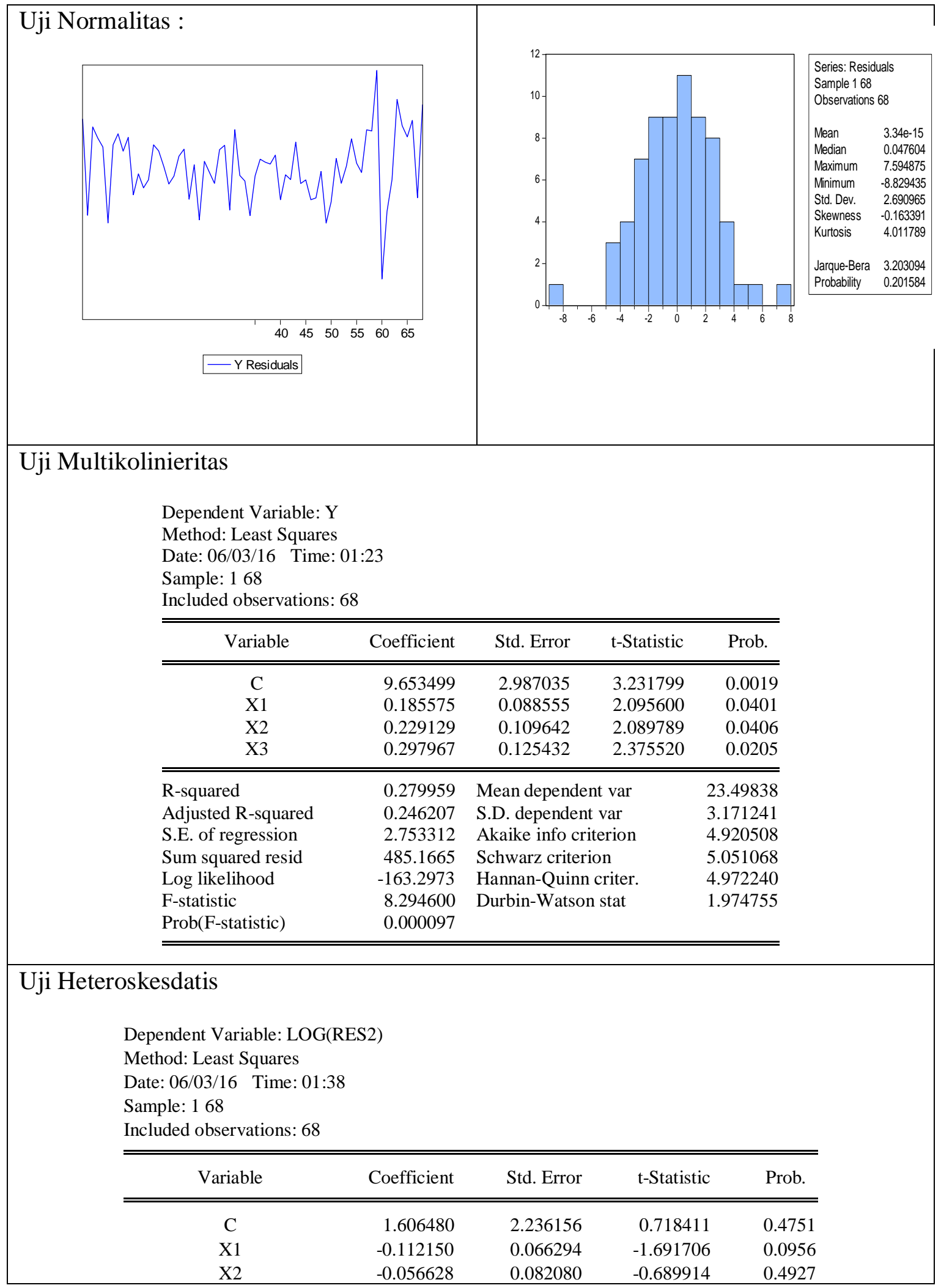


I-Economic Vol. 4. No 2. Desember 2018

Faktor yang Mempengaruhi Pola Konsumsi .... Amir Machmud

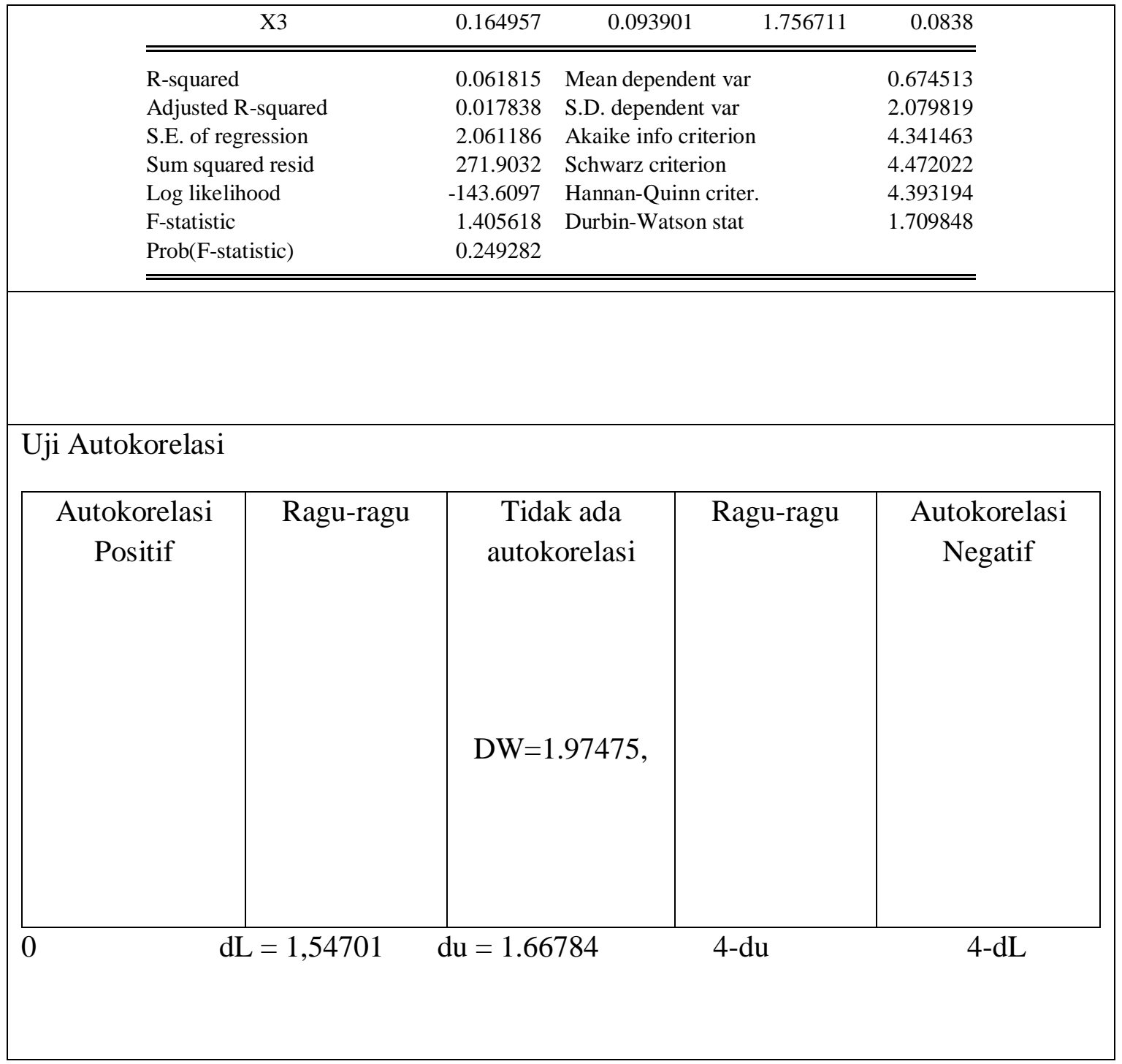

Berdasarkan hasil uji asumsi klasik pada Tabel 1 tampak bahwa semua data yang diuji tidak melanggar asumsi klasi atau sering disebut dengan BLUE, Dengan demikian hasil pengujian dapat tersebut dapat menjelaskan bahwa model regresi dapat digunakan untuk menganalisis faktor-faktor yang mempengaruhi pola konsumsi masyarakat miskin di Kota Bandung.

Hasil regresi Brganda

\begin{tabular}{|c|c|c|c|c|}
\hline$\hat{\mathrm{Y}}$ & $=9.65349$ & $+0.185575 X_{1}$ & $+0.229129 X_{2}+$ & $0.297967 \mathrm{X}_{3}$ \\
\hline $\mathrm{Se}$ & $=(2.987035)$ & $(0.088555)$ & & $(0.125432)$ \\
\hline & & & $(0.109642)$ & \\
\hline Hitung & $=(3.231799)$ & $(2.09560)$ & (2.089789) & (2.375520) \\
\hline F hitung & $=8,294600$ & & & \\
\hline $\mathrm{R}^{2}$ & $=0.279959$ & & & \\
\hline Adj R & $=0.246207$ & & & \\
\hline
\end{tabular}


I-Economic Vol. 4. No 2. Desember 2018

Faktor yang Mempengaruhi Pola Konsumsi .... Amir Machmud

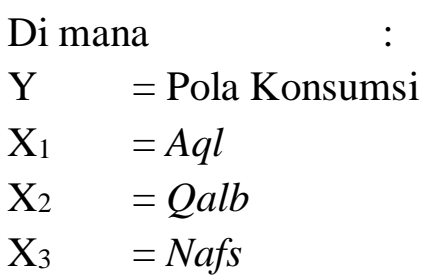

Berdasarkan hasil regresi tampak bahwa secara bersama-sama pola konsumsi masyarakat miskin di kota Bandung dipengaruhi oleh Aql, Qalb dan Nafs. Hal ini tampak dari Uji $\mathrm{F}$ yang menunjukkan nilai $\mathrm{F}$ hitung lebih besar daripada $\mathrm{F}$ Tabel. Adapun besarnya pengaruh Aql, Qalb dan Nafs terhadap pola konsumsi masyarakat miskin di Kota Bandung sebesar 27,99 persen. Ini memberikan implikasi bahwa pola konsumsi masyarakat miskin di Kota Bandung sebesar 27,99 persen dipengaruhi oleh Aql, Qalb dan Nafs, sedangkan sisanya sebesar persen dipengaruhi oleh faktor lain yang tidak diteliti seperti tingkat pendapatan, gaya hidup dan tingkat pendidikan.

Jika melihat besaran koefisien regresi tampak bahwa Aql, Qalb dan Nafs memiliki slope yang positif. Ini berarti bahwa ketiga variabel tersebut memiliki pegaruh yang positif terhadap pola konsumsi masyarakat miskin di Kota Bandung. Secara berturut-turut besaran koefisien regresi adalah Nafs, Qalbu dan Aql. Ini memberikan gambaran bahwa pola konsusmsi masyarakat miskin di kota Bandung masih didominasi oleh nafs. Seperti diketahui bahwa Nafs memiliki beberapa makna yaitu nafs dalam arti yang baik ketika ia dikelilingi oleh sifat yang baik, dan akan menjadi nafs yang buruk ketika dikelilingi oleh sifat yang buruk. Secara jasmani, nafs merupakan penghimpun sifat tercela yang ada pada diri manusia, yang bertempat di alam ketidaksadaran. Secara ruhani, nafsu merupakan diri manusia dengan berbagai sifatnya, sesuai dengan keadaannya.

Berkaitan dengan kajian ini, hasil ini memberikan implikasi bahwa pola konsumsi masyarakat miskin di kota Bandung secara jasmani belum mampu menahan hasrat mengkonsumsi dan belum rasional. Hasil penelitian yang menunjukkan bahwa Nafs berpengaruh positif dan signifikan terhadap pola konsumsi masyarakat, hal ini dapat dilihat melalui uji signifikan secara parsial dimana nili $\mathrm{t}$ hitung lebih besar daripada t tabel pada level of signifinant 0,05 artinya semakin tinggi Nafs muthmainnah maka pola konsumsi syariahnya akan terjaga dari hal-hal yeng bersifat israf. Sebaliknya jika semakin tinggi nafsu lawwamah (jiwa yang mencela) dan nafsu amarah, maka semakin sulit mengendalikan sifat-sifat konsumtif dalam melakukan konsumsi

Qalbu merupakan kendali rasa manusia. Ketika dalam berkonsumsi seseorang memperhatikan qalbnya maka ia akan senantiasa mengalokasikan dananya bukan hanya untuk kepentingan individual, tetapi termasuk pula kepentingan sosial. Adapaun qalbu dapat dipengaruhi oleh: keimanan seseorang yang dilihat dari gaya hidup, selera 
I-Economic Vol. 4. No 2. Desember 2018

Faktor yang Mempengaruhi Pola Konsumsi .... Amir Machmud

perilaku, konsumsi sosial (ijtma'iyah), zakat,infak, sedekah, konsumsi pribadi (syakhsiniyah) ihsan kepada Allah ihsan kepada sesama manusia memperhatikan prinsip-prinsip konsumsi islam.

Berdasarkan hasil penelitian menunjukan bahwa Qalb berpengaruh positif dan signifikan terhadap pola konsumsi masyarakat miskin di Kota Bandung. Hal ini tampak dari nilai t hitung lebih besar daripada $t$ tabel pada level of signifin $5 \%$. Kondisi ini memberikan makna bahwa semakin tinggi qalb semakin baik / tinggi pula pola konsumsi islami yang dijalaninya. Ini berarti bahwa pola konsumsi masyarakat miskin di kota Bandung dalam mengalokasikan sumber daya yang dimiliki cenderung memperhatikan kepentingan sosial lainnya. Dengan perkataan lain bahwa masyarakat miskin di Kota Bandung sudah mampu mengalokasikan konsumsi bukan hanya untuk kepentingan dirinya saja melainkan juga memperhatikan konsumsi sosial.

Aql/rasionalitas (X1) merupakan salah satu faktor yang mempengaruhi pola konsumsi seseorang. Semakin tinggi tingkat rasional seseorang dalam mengalokasikan pendapatannya dan mengunakannya untuk kebutuhan dan kepentingan duniawai dan ukhrowi maka ia telah mengimplementasikan pola konsumsi secara islam. Rasional artinya seseorang mampu mengatur dan mengalokasikan pendapatan yang dimiliki untuk kebutuhan yang telah direncanakan sebelumnya, ketika seseorang bersikap rasional maka ia telah berlaku adil dalam menempatkan pendapatannya. Berdasarkan Table 3.1 tampak bahwa Aql atau rasionalitas masyarakat penerima zakat di Kota Bandung berada pada kriteria cukup rasional artinya bahwa mereka dalam membelanjakan pendapatannya untuk konsumsi tidak berlebihan dan bermewahmewahan. Adapun indikator dari Rasionalitas (Aql) menurut M.Muflih (2006:53) Berkonsumsi dengan berdasarkan etika islam, Logis dan analitis, Adil, tidak bermewahmewahan dan Sederhana, menggunakan Preferensi / skala prioritas dalam berkonsumsi.

Berdasarkan hasil analisis data dan uji hipotesis diketahui bahwa aql berpengaruh positif dan signifikan terhadap pola konsumsi masyarakat. Hal ini dapat dilihat dari hasil uji signifikansi yang lebih kecil dari 0,05. Artinya, semakin tinggi aql / semakin baik rasionalitas seseorang maka akan semakin baik pula pola konsumsinya, pola konsumsi dalam penelitian yang dimaksud adalah pola konsumsi yang sesuai dengan aturan dan norma islam, semakin ia menggunakan aql ketika berkonsumsi maka pola konsumsinya akan lebih terjaga dari hal-hal yang bersifat mudhorot atau tidak bermanfaat. Hal ini didukung pula dengan $45.83 \%$ responden berada pada kriteria aq $l$ yang sangat tinggi, dan 33,33\% responden memiliki kriteria aql yang tinggi.

Hal ini selaras dengan para peneliti sebelumnya ${ }^{6}$ manusia perlu berpikir dengan Aql berdasarkan standar rasio tertentu agar ia rasional. Manusia menghitung,

\footnotetext{
${ }^{6}$ Muhamad Muflih Muhamad Muflih, Perilaku Konsumen dalam Perspektif Ekonomi Islam (Jakarta, RajaGrafindo, 2006)

Abdur Ruquib " Islamic Banking \& Zakat-An Alternative Approach to Poverty Reduction in Bangladesh”. Journal of Islamic Economics, Banking and Finance, Vol 7 No 2, april-June 2011
} 
mengukur, menalar, menganalisis, dan menafsirkan sesuatu dengan akalnya. Perhitungan dan pengukuran akan tepat apabila menurut ukuran rasio yang benar. Pada tahap ini manusia mengupayakan apa yang dipikirkannya dilakukan secara analitis - logis agar memiliki nilai guna bagi kelangsungan hidupnya. Berpikir analitis-logis diartikan sebagai kegiatan berpikir menurut suatu pola tertentu, atau menurut logika tertentu. Manusia yang berpikir hanya untuk kepentingan jangka pendek (sesaat) tanpa memperhatikan aspek jangka panjang mungkin logis tetapi tidak analitis. Karena dengan mengabaikan jangka panjang dia tidak mempersiapkan diri mengahadapi konsekuensi yang tidak ringan. Dengan demikian, sifat analitik ini berguna dalam menemukan kebenaran dan manfaat jangka panjang karena pada akhirnya seseorang dapat membedakan mana yang baik dan mana yang buruk. Dengan demikian apa yang diinginkan akal ialah segala sesuatunya terukur, terhitung dan teranalisis dengan baik.

\section{Simpulan}

Berdasarkan uraian pada bab pembahasan, sebagai penutup dari kajian ini dapat ditarik kesimpulan sebagai berikut:

1) Pola konsumsi masyarakat miskin di Kota Bandung termasuk dalam kategori cukup islami, dipandang dari segi aql, nafs dan qalb.

2) Pola konsumsi masyarakat Kota Bandung sebesar 27,8 persen dipengaruhi oleh faktor nafs, Qalb dan Aql., sedangkan sisanya dipengaruhi oleh faktor yang tidak diteliti dalam perpektf islam. Ketiga faktor tersebut secara bersama-sama dan parsial memiliki pengaruh yang positif dan sginifikant secara statistik..

Berdasasarkan kesimpulan tersebut, saran yang dapat direkomendasikan dalam kesempatan ini adalah sebagai berikut:

1. Berperilaku sederhana dalam konsumsi, karena pola konsumsi yang sesuai dengan prinsip islam adalah pola konsumsi yang tidak bermewah-mewahan dan tidak boros. Sesuai dengan Firman Allah dalam surat surat Al-Israa yang artinya: "Sesungguhnya pemboros-pemboros itu adalah saudara-saudara syaitan dan syaitan itu adalah sangat ingkar kepada Tuhannya."

2. Selalu tanamkan dalam diri bahwa sesungguhnya harta yang diberikan oleh Allah hanyalah titipan semata, maka selayaknya harus dijaga sebagaimana pemiliknya harapkan, agar tidak terlalu terlena dengan pendapatan yang tinggi. Seperti firman Allah dalam surat (Al-Munafiqun: 10). "Dan belanjakanlah (dermakanlah) sebagian dari rezeki yang Kami berikan kepada kamu sebelum kematian datang kepada salah seorang di antara kamu..." 
I-Economic Vol. 4. No 2. Desember 2018

Faktor yang Mempengaruhi Pola Konsumsi .... Amir Machmud

3. Tidak mudah terpengaruh oleh mode, diskon dan segala bentuk promosi barang dan jasa yang sebenarnya tidak terlalu mendesak untuk dibeli yang hanya akan membawa pada perilaku yang konsumtif,

\section{Daftar Pustaka}

Abdur Ruquib, "Islamic Banking \& Zakat-An Alternative Approach to Poverty Reduction in Bangladesh". Journal of Islamic Economics, Banking and Finance, Vol 7 No 2, april-June 2011

Alas, R.,"The Impact of Work-Related Values on the Readiness to Change in Estonian Organization", Journal of Business Ethics, Vol. 86, pp. 113-124, 2009

Amir Machmud, Eeng Ahman, Navik Istikomah, "Optimalization of Qardhu Hasan Sharia Bank toward Decreasing Poverty in Bandung". Proceedings of the 2016 Global Conference on Business, Management and Entrepreneurship, Atlantis Press, 2016

Amir Machmud, "Sharia Microfinance, Poverty, Indonesia", Proceedings of the 2nd International Conference on Economic Education and Entrepreneurship August 33, , in Bandung, Indonesia 2017

Bappenas "Perkembangan Keuangan Mikro Untuk Kemiskinan". http:// ditpk.bappenas.go.id/ ?nav $=4 \& m=$ content $\& s=$ artikel $\& a=v i e w \& i d=309(2010)$

Emerson and McKinney, "Importance of Religious Beliefs to Ethical Attitudes in Business", Journal of Religion and Business Ethics, Vol 1. Issue 2. , 2010.

E.Suprayitno dkk "The imfact of Zakat on Aggregate Consumption in Malaysia". Journal of Islamic Economics, Banking and Finance, 56 Vol. 9 No. 1, Jan - Mar 2013

Foxall, R. G., Sigurdsson, V. "Consumer Behavior Analysis: Behavioral Economics Meets The Marketplace”, The Psychological Record, Vol. 63, pp. 231-238. 201

Komaruddin Hidayat, Psikologi Beragama, Menjadikan Hidup Lebih Nyaman dan Santun, (Jakarta: PT Mizan Publika, 2006, hlm. 53).

Lee Roy Beach and Terry Connolly, The Psychology of Decision Making, USA, Sage Publication, 2005

Muhamad Muflih, Perilaku Konsumen dalam Perspektif Ekonomi Islam (Jakarta, RajaGrafindo, 2006)

Mokhlis, S., "Relevancy and Measurement of Religiosity in Consumer Behavior Research", International Business Research, Vol. 2, No.3, p. 75- 84, 2009

Rashid, M. Z. and Ibrahim, S. "The Effect of Culture and Religiosity on Business Ethics: A Cross-Cultural Comparison”, Journal of Business Ethics, 82, pp. 907917, 2008,1

Rohman \& Taufik Ismail, "Consumption Ritual in Javanese Wedding Ceremony: Ethnography Research in Indonesian Regency-Kabupaten Ngawi, Asia Pasific Management and Business Application, 2, (2) 2013,'

Scott John Vitell, et.al, "Religiosity and Moral Identity: The Mediating Role of SelfControl", Journal of Business Ethics, 88, pp 604; 2009 
I-Economic Vol. 4. No 2. Desember 2018

Faktor yang Mempengaruhi Pola Konsumsi .... Amir Machmud

Warde, A.. "Consumption and Theories of Practice", Journal of Consumer Culture, Vol. 5, No. 2 pp. 131-153. 2005

Yusuf al-Qardhawy Konsep Islam dalam Mengentaskan kemiskinan. (Surabaya, Bina Islam. 1996 ) 